\title{
Harm Reduction or PSychedelic Support? Caring for Drug-Related Crises at Transformational Festivals
}

\author{
$\bullet$ Feature Article $\longrightarrow$ \\ DEIRDRE RUANE \\ UNIVERSITY OF KENT (UK)
}

\begin{abstract}
Many of the EDM events known as "transformational festivals" provide psychedelic support spaces: volunteer projects caring for festivalgoers undergoing difficult drug experiences. Mostly drawn from the festival community, many volunteer carers ("sitters") subscribe to psychedelic culture discourse which frames these substances as aids to personal growth if handled appropriately. However, within the dominant paradigm of international drug prohibition, support projects must employ the contrasting discourse of harm reduction in order to gain access to events, visibility to festivalgoers, and integration with other support staff. Harm reduction, a paradigm for the care of drug users which began as a grassroots heroin addict advocacy movement, has since become associated with neoliberal, medicalised views of drugs, drug users and the self. This article considers how psychedelic support workers negotiate this discourse dichotomy in the course of caregiving, within differing national and local drug policy climates. Early findings are presented from ethnographic fieldwork as a psychedelic support volunteer with three organisations at seven festivals, combining participant observation and in-depth interviews with nineteen support workers. Events in the UK, the US and Portugal were studied due to these countries' contrasting policy regimes. Points of conflict between the psychedelic and harm reduction discourses were found to create tensions both within the support organisations and in their relations with on-site medics, security guards, festival organisers and police. The findings suggest that mainstream harm reduction discourses may be a poor fit for psychedelics and that risks inhere in their adoption by festival support spaces, such as abjection of drug users in difficulty which may create a trust-damaging divide between users and workers.
\end{abstract}

KEYWORDS: transformational festivals, psychedelics, recreational drugs, harm reduction

DeIRDRe RuAne is a doctoral researcher at the University of Kent's School of Social Policy, Sociology and Social Research. Her research interests include drug harm reduction, festival cultures and EDMCs. She has been published in Transforming Cultures eJournal and the forthcoming anthology by Dave King et al., Neurotransmissions: Essays on Psychedelics from Breaking Convention. Strange Attractor Press.

Dancecult: Journal of Electronic Dance Music Culture 7(1): 55-75

ISSN 1947-5403 @2015 Dancecult http://dj.dancecult.net http://dx.doi.org/10.12801/1947-5403.2015.07.01.03 


\section{INTRODUCTION}

Tuesday 5 August, 2014, Boom Festival, Portugal. Late afternoon. Now that the Sacred Fire has been lit, the first beats from the Dance Temple roll across the hillside to meet the onrushing crowd. The heat is punishing, but inside the Temple we find shade and cool falling mist. Faces turn up to receive it. It's finally begun. Many of the crowd, swept up in the moment, drop acid-or a blue fractal blotter they think is acid-round about now, and by midnight psychedelic support space Kosmicare is having its busiest night on record.

Within the compound, near the centre of the site, a full team of sitters and others not on shift, pulled in to help, are hard at work. I'm with a young Irishman who thinks he's in hell. It's like psychedelic A\&E: visitors are arriving on foot and in jeeps or buggies, alone or brought by friends, medics or security. The list on the whiteboard by the front desk, where visitors are checked in and their detailed admission forms are filled in, gets longer and longer. Most of them are having classic LSD trips: a familiar sequence of dissolution and gradual reassembling. But by morning we are wondering why a few just don't seem to be coming down.

That's when people from CheckIn-the government-endorsed drug checking lab that's been running all night by the main dance floor - arrive with their detailed findings and an explanation. What the visitors thought was LSD is in fact DOx, a family of psychedelic amphetamines with twenty-five to thirty-six hour effects. As we formulate a strategy for visitors on DOx, CheckIn are posting warning signs all over the site.

Burn Night, 31 August, 2014, Burning Man, Nevada, USA. After watching the most stubborn Man in the history of Burns finally collapse I arrive on shift at the Zendo "psych support" space at 2:00am. Inside it's warmly lit, with piles of blankets on raised sleeping platforms, and skilled therapists stand ready to assist. But it's buried down a dark side street with minimal footfall, out past 2.30 and E, and because of the hostile nature of Nevada law enforcement, its advertising has been evasive and ambiguous. It's almost empty. Some Roamers are being dispatched to the biggest and loudest dance camps, to tell people about the Zendo and offer to sit with anyone they find having a crisis. They will find no one who admits to this.

The shift leader quietly points me towards a guy sitting cross-legged on the floor, swaying and moving his hands fluidly through the air. After we've talked for a while I ask him what he took. He closes up and pulls away. "I don't see why I should tell you that", he says, "it's irrelevant to my personal quest".

Saturday afternoon, 26 July, 2014, Secret Garden Party, UK. Kosmicare UK is tucked away in the most remote corner of the festival site, far from the medical and welfare tents, behind a fairground swing ride that pumps out disco. We're expecting a quiet shift. Then a dozen or so late-teenage boys and girls arrive, supporting a terrified 
girl who is convinced the security guards intend to strip-search her. They've all taken what they think is MDMA. One of the volunteers, a chemist, examines their baggie and decides it's pentedrone, a recently synthesised cathinone associated with compulsive binges and stimulant psychosis. He's almost right-months later, results from a postal testing service confirm it's pentedrone's closest relative, alpha-PVP-but at the time there's no way to check. Meanwhile I watch them follow their friend down into the same pit of paranoia: black magic, conspiracy, harassment, sexual violence, incontinence and shame. The three of us on shift work flat-out long into the night. Sleep will resolve the problem, but they think we're part of the conspiracy, and they won't sleep here till we've won their trust.

The next afternoon I head over to medical and welfare. We were told they'd been briefed, but the ones on duty haven't heard of us. There have been hundreds of cases like the ones we had, distressed and paranoid in eerily similar ways. But the brusque nurse on the triage desk won't believe that it's not MDMA. She insists it's "the bad batch the police told us about", so pure that people are overdosing. I try to tell her that the effects we saw were nothing like MDMA overdose, and anyway there's bound to be much more than one bad batch at a festival this size-but she's busy, and no longer listening.

Psychedelic support involves the provision of a "care space" or refuge from the sometimes overwhelming atmosphere of EDM and other events, with volunteer carers known as "sitters" providing support to participants having difficult drug experiences. The purpose of the space is to assist participants towards the resolution of these experiences, and relatedly to alleviate the burden of psychedelic crises upon on-site medics who are often ill-equipped to handle them. Most often appearing at "transformational festivals", these spaces are also known as "psychedelic welfare" or "psychedelic harm reduction".

"Psychedelic harm reduction" is a somewhat contentious phrase. Harm reduction is a paradigm for the care of drug users offering an alternative to approaches which focus on criminalisation and abstinence, seeking to reduce the harm rather than the use of drugs. However, over the years the paradigm has changed from a grassroots movement driven by users to one shaped by discourses of neoliberalism and medicalisation. The discourse of psychedelic culture, expressed in the ideologies of transformational festivals, conflicts with that of mainstream harm reduction in its evaluation of "drugs", in its conception of the drug user, the self and the other and its understanding of the nature of the relationship between drugs workers and the users they support. While psychedelic support workers tend to subscribe to the psychedelic culture discourse, they must work within the harm reduction paradigm to be permitted to operate at events, leading to tensions which affect their care practices. This complex situation is further impacted by the effects of national and local drug policy.

As part of my doctoral research, I spent the summer of 2014 volunteering with, observing and conducting interviews with three psychedelic support organisations, at festivals in three countries with contrasting legal climates. These were Kosmicare UK (UK), the Zendo Project (US) and Kosmicare (Portugal). This paper will use early fieldwork findings and 
relevant literature to compare the discourse of psychedelic culture and the transformational festival with that of harm reduction, and consider ways in which the tension between the two discourses affects the support organisations.

First, the scene must be set. Transformational festivals have a distinctive culture which sets them apart from other EDM festivals, focusing on self-transformation and communitybuilding through dance, group ritual and co-creativity. Psychedelic support plays an important role in this "transformation". The following section draws upon both scholarly and scene writing, along with my own observations during fieldwork, to provide a brief introduction to the transformational festival.

\section{Transformational Festivals, IDentity and the Collective}

Transformational festivals are an emerging category of events with some or all of the following features: EDM, including psychedelic dance music; visionary art; an emphasis on creative participation rather than spectatorship; Leave No Trace or permaculturebased operating principles; seminars, workshops and lectures; green politics and/or social activism; and a remit of personal and social transformation (Krasnow 2012), along with widespread use of psychedelics and group ritual. Leung (2010) positions the American and Canadian West Coast as the current centre of the movement, though transformational festivals can be found worldwide.

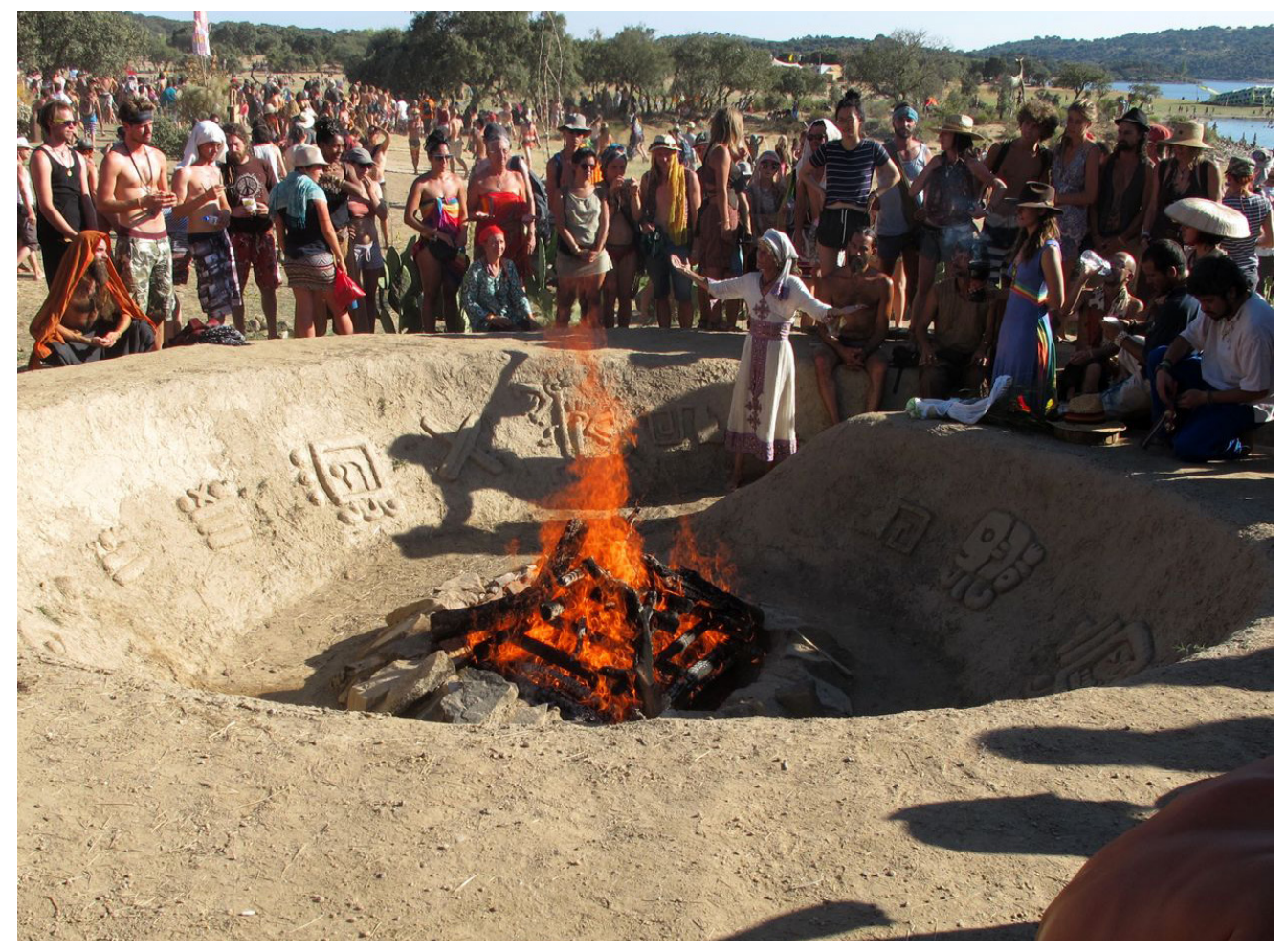

Figure 1. The Sacred Fire, Boom. Photo credit: author (2014). 
Several cultural currents converge in the transformational festival, a non-exhaustive account of which will be given here. One is Burning Man, at which a temporary community known as Black Rock City is built in the Nevada desert for a week each year. Burning Man began as an anarcho-punk event emphasising art, ritual and co-creativity. Dance music camps arrived later, becoming integral to the event (Jones 2011:84-8). Another influence on the transformational festival was the Goatrance movement, which was seeded in the late 1960s with "spontaneous dance jams" on the beaches of Goa mounted by "freaks" who had settled there. By the 1970s, these events had evolved into full-moon dance gatherings (St John 2012: 34-5). As the Goa scene itself declined in the 1990s and 2000s, psychedelic events inspired by the Goa aesthetic and philosophy began to spring up worldwide, such as Boom, Ozora and Envision festivals. In the UK, the transformational festival scene that supports events like Sunrise Celebration, Waveform and Alchemy is rooted in the Free Festival/New Age Traveller movement of the 1970s, and was further fuelled by 1980s-90s UK rave and its legendary outdoor events (Dearling 2012: 14). Migrating across the Atlantic in the mid1990s, rave combined with "progressive currents" on the US West Coast to bring about a proliferation of transformational festivals there (Leung 2010).

The "transformation" which is said to occur at these events has various vectors. Social transformation may arise from connections made, information exchanged and skills learned at events. In constructing festival spaces, crews and festivalgoers engage in utopics: a form

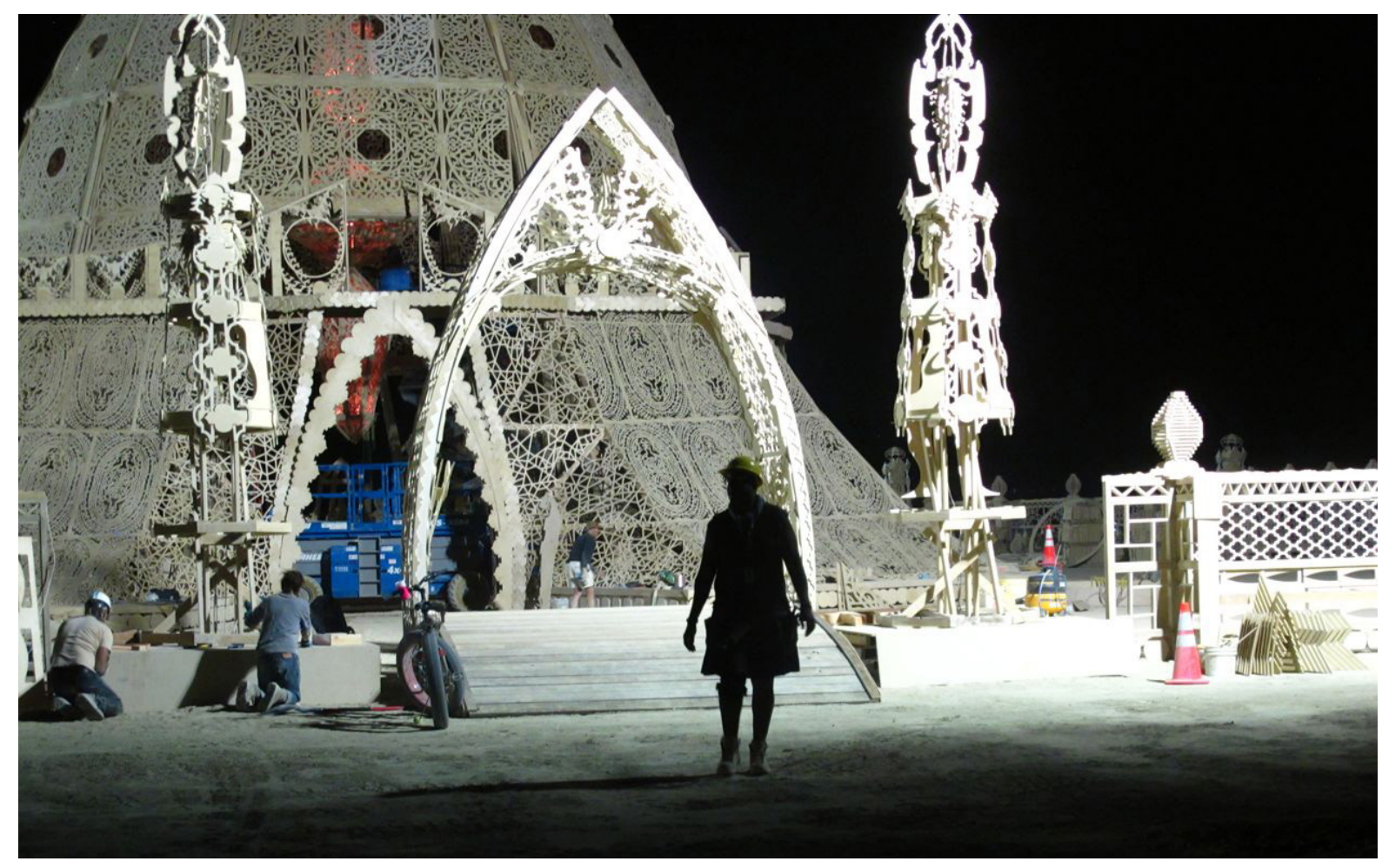

Figure 2. Constructing the Temple, Burning Man 2014. Photo credit: author (2014). 
of "spatial play" involving the construction of physical representations of "the good society" (Marin 1984: 6-12; Hetherington 1998: 328). Though these representations are necessarily temporary and often hotly contested (St John 2013), they enable the formation of activist networks which can persist on return to the "real world", in areas such as non-market economies (Kozinets 2002: 20-38), environmentalism (Purdue et al. 1997: 660-4), or use of festival-learned skills to assist disaster relief efforts (Jones 2011: 176-8).

Alongside the transformational festival's utopian social aspirations, and inextricable from them, is the idea of the transformation of self through the festival experience and the non-ordinary states of being it facilitates. Numerous authors, for example Gilmore (2010: 13), Tramacchi (2000: 206) and Pike (2011: 158), have framed the festival state by way of Victor Turner's theory of liminality (Turner 1969: 95), in which a threshold is crossed into a "betwixt and between" state where everyday rules and the flow of normal time are suspended and new social roles can be assumed. However, St John's reconfiguration of Turner's theory (2001) offers a better purchase on transformational festivals, acknowledging the wild heterogeneity of peak experiences and the central role of embodiment.

Perhaps the most common image of the collective, embodied spirit of transformational festivals is that of the dance floor, on which ego boundaries are said to dissolve, resulting in ecstatic experiences of communion mediated by the rhythms of psytrance and other EDM, and often assisted by consumption of psychedelics. Duffy et al. (2011:23) describe how an "emotional response of belonging" arises from communication "through pulse", such as that engaged in by a dancing crowd moving in synchrony. As St John (2012: 183) writes, in spaces like the Dance Temple at Boom Festival "the boundaries that separate people from each other and from the world are subject to liquidation".

This merging with the collective may involve a temporary suspension of-or deliberate flight from-everyday identity as a unitary neoliberal subject (as described by Rose 1996: 41) constantly engaged in processes of self-monitoring, self-governing and efficiency maximisation. As St John (2012: 116) writes, one becomes "unburdened of disciplined, voluntary modes of subjectivity". While one is thus unburdened, a different subjectivity reveals itself. Experiences of selfhood within the space of the transformational festival are characterised by fluidity, integration with others and periods of dissolution into group ecstatic states-an experience which is arguably the driving force behind the transformational festival's collectivist, utopic aspirations.

However, the process is not always smooth. As Echenhofer (2012) found, the phase of dissolution early in a psychedelic experience can be disturbing and involve an upwelling of difficult emotions. In the right setting, and especially if support is given, this crisis phase can give way to a "healing catharsis" (Leung 2010) which resolves into an experience of reintegration, both in oneself and with the collective. This process is highly valued within transformational festival culture and seen as an opportunity for growth (Zendo 2013: 2). Thus Leung (2010) sees the provision of psychedelic support as integral to the culture. 


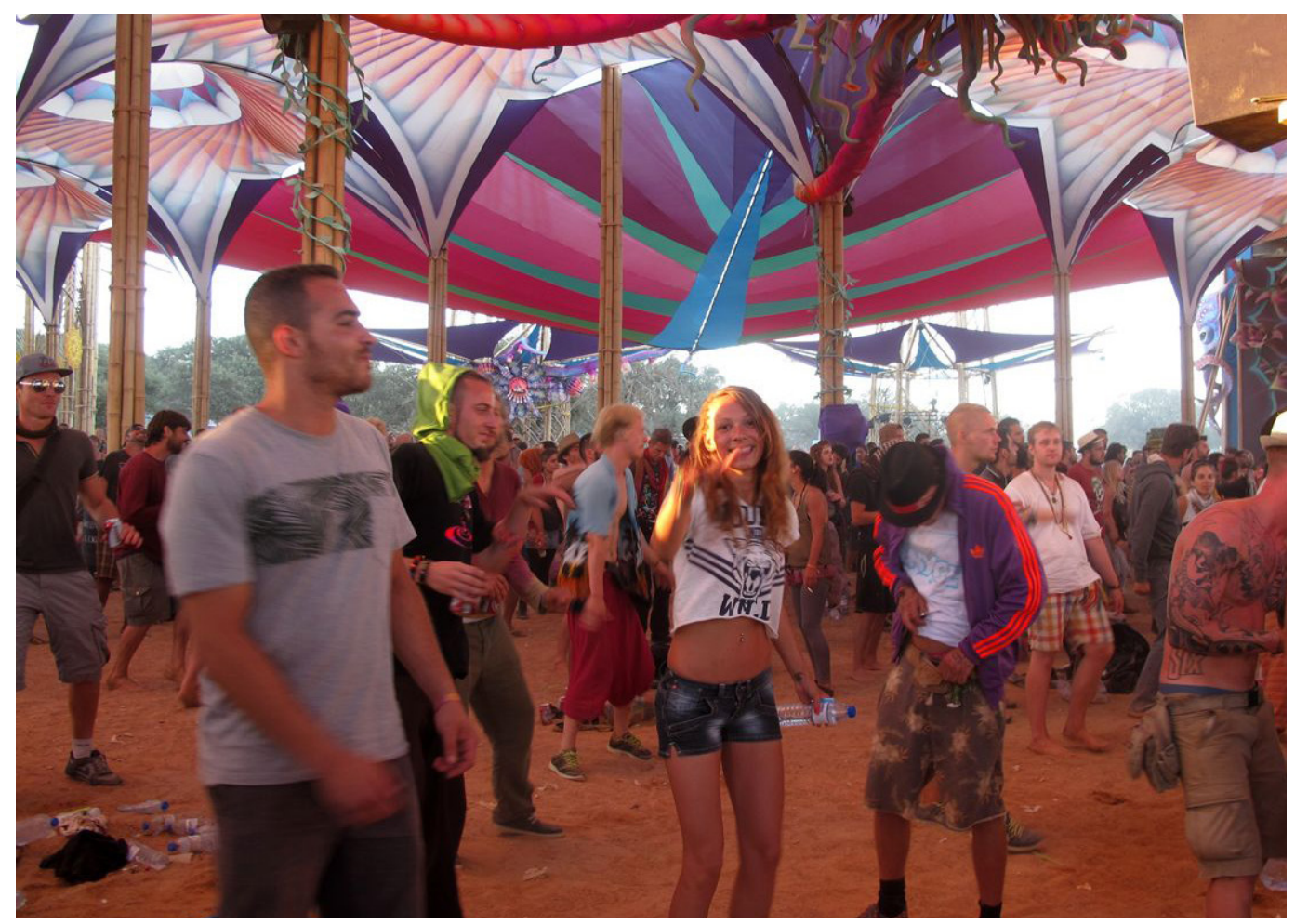

Figure 3. Sunrise at the Dance Temple, Boom. Photo credit: author (2014).

In the context of these values, drug consumption preferences in transformational festival culture differ from those, for instance, at corporate EDM events. Informal surveys of festivalgoers during fieldwork in the UK and Portugal, alongside data from drug checking facilities, allowed me to build up a picture of supply and demand based on respondents' stated preferences and on which substances they had noticed were being sold within the festival. "Classic" psychedelics such as LSD, mushrooms and forms of DMT such as the smoking blend changa are the most highly valued, and along with MDMA, the most sought after. Cannabis is ubiquitous, and lesser-known synthetic psychedelics such as the 2C family are also popular. Stimulants such as speed and mephedrone are present, but less popular than at more corporate events. Ketamine provokes widespread ambivalence: many profess to dislike it but it is nonetheless widely used. Most "hard" drugs such as heroin and crack-though not cocaine, at least not unanimously-are shunned by transformational festivalgoers, many of whom distance themselves emphatically from users of addictive drugs. Finally, novel psychoactive substances (NPS) such as the DOx family, NBOMe and alpha-PVP, are rarely sought or sold explicitly; rather, they tend to be sold as one of the "classics". Successive waves of bans on psychoactive substances make the ongoing synthesis or rediscovery of still-legal NPS an attractive proposition for the drug trade. NPS have little history of human use and thus carry unknown risks. 
Several key aspects of psychedelic culture discourse will be foregrounded in this analysis, as they are central to the work of psychedelic support projects. These are views of the self; views of drug use and its value; attitudes to drug users and their relationship with support workers; and conceptions of the central purpose of the support space. The self is here regarded as transpersonal, holistic, part of a collective, and capable of dissolving and reforming, with a porous self/other boundary. In theory, drug users undergoing intense altered states are seen as engaged in valuable internal processes, and thus deserving of respect (Zendo 2013: 2). As fellow scene members, support workers are considered to be the peers and equals of those they support. Finally, the facilitation of potentially beneficial psychedelic processes with the aim of personal growth is the core purpose of the support space. As we shall see, each of these points contrasts sharply with mainstream harm reduction discourse.

The next section provides a brief introduction to the support projects, their work within the transformational festival milieu and the differing pressures of local and national drug policy upon them. There is little scholarship concerning the projects as yet, so this account rests upon memoirs of and conversations with support workers, along with my own field observations.

\section{Ground Crew: Psychedelic Support Projects at Work}

Psychedelic support volunteers are drawn from festival culture. Many are psychologists, psychiatrists, counsellors and other mental health professionals; others are community drugs workers; some simply have extensive experience with psychedelics. Their remit of care covers all difficult drug experiences for which medical attention is not required. While most work within the care space, mobile teams, such as the Vibe Patrol at Boom or the Zendo Roamers at Burning Man, circulate on dance floors to "keep the vibe high", providing primary care, water, reassurance and sometimes transport to the care space.

The first step in a visitor's care is establishing whether they require medical attention, referring them to medical staff if this is the case. If not, care strategies are shaped by what the visitor is believed to have taken, and thus the profile and estimated duration of the effects. For those deemed to be undergoing a psychedelic crisis arising from a normal dosage of a well-known substance, care focuses on the facilitation of the visitor's internal process. It may start with the provision of basic comforts such as blankets, water or tea and a private, low-stimulus space if desired. Subsequently, sitters remain with visitors, talking, listening or simply sitting quietly with the visitor as desired. The aim is to create an atmosphere of safety in which the visitor feels able to confront and process difficult emotions. In transformational festival culture, dance is seen as a powerful catalyst of this internal work. Thus some care techniques use movement and dance to help visitors towards catharsis. Zendo training includes a segment on "bodywork" techniques which encourage the visitor to focus on and amplify involuntary movements, and Kosmicare sometimes features a separate space in which visitors can dance if desired. 
Most such cases resolve without problems given support, comfort and time. However, many others are less predictable. Visitors may have taken too much of one substance or an incompatible combination of several; been unwittingly spiked; be suffering from difficult physical conditions, lack of food or sleep; or been sold a more harmful substance than the one they expected. Care of these cases focuses on the minimisation of health impacts. Visitors are monitored closely and may be medicated if their case does not seem to be resolving, though this is avoided where possible. In rare cases, support workers may decide to keep visitors within the compound if they are thought to be a risk to themselves or others.

Formulating a care strategy with the right balance of process facilitation and damage control is easier in policy climates where drug checking is possible. Where checking is prohibited, support staff must rely on guesswork and experience. Experience, however, is inadequate in the face of the constant influx of NPS being sold as more familiar drugs. Punitive climates which lack checking facilities, and where transactions must be performed hastily and surreptitiously to avoid police, create favourable conditions for the sale of partly or wholly adulterated drugs, recalling Rhodes' (2009) characterisation of governments as "agents of harm production".

Some of the roots of psychedelic support lie in the Free Festival movement of the 1970s in the UK, which saw the setup of Festival Aid, later Festival Welfare Services, a governmentfunded organisation linked to drugs charity Release and run by members of the Traveller movement (Dearling 2012: 65-80). Others spring from Goa, where Karin Silenzi de Stagni, now the manager of Kosmicare UK, set up a popular "nest" space at beach parties in the late 1990s (De Stagni 2013). Elsewhere, in 2001, MAPS—the Multidisciplinary Association for Psychedelic Studies-began to provide support at US festivals like Burning Man. A few years later, taking advantage of decriminalisation in Portugal, Portuguese government agency SICAD invited MAPS to set up Kosmicare at Boom (Emerson et al. 2014: 34), inspiring De Stagni to start a UK branch. Other projects include Daath Psy-Help in Hungary (Móró and Rácz 2013: 1), Alice Project and Eclipse in Germany and mobile drug checking services like Spain's Energy Control and Austria's CheckIt! which provide some psychedelic support as an adjunct to their lab work. However, this paper focuses on Kosmicare, the Zendo Project (also a MAPS initiative) and Kosmicare UK.

\section{KOSMICARE}

Portuguese project Kosmicare had approximately sixty volunteers, many of whom were mental health professionals, at Boom festival in 2014. Volunteers work in shifts of six with experienced shift leaders and a medical team on hand. Their compound, whose structures are provided by the festival, is central and well publicised on maps and brochures. They share detailed data with CheckIn, a front-of-house (that is, providing feedback to users on a short timescale) drug checking laboratory with state-of-the-art testing facilities located beside the Dance Temple, Boom's central dance floor. 
The Portuguese policy environment is perhaps the most liberal in the world. In 2001, as documented by Hughes and Stevens (2010: 1001-18), possession of a small amount of any illicit drug was changed from a criminal offence to an administrative one and a battery of government-sponsored harm reduction programs were rolled out. Medicalisation was at the core of the approach, with drug use portrayed as a public health issue. MAPS and SICAD launched Kosmicare at Boom the following year (Emerson et al. 2014: 34). While psychedelic support projects in many other countries struggle to justify their existence to the authorities, Kosmicare is heartily endorsed by the Portuguese government, and Boom organisers give Kosmicare unprecedented visibility and publicity on-site.

However, within this more relaxed policy climate, some tensions still arise between the psychedelic discourse to which the majority of support workers subscribe and the medicalised, harm-reduction-based approach of Portuguese drug policy. These mostly concern moves towards formalisation of the care space and will be explored later.

\section{THE Zendo PRoject}

In the US, MAPS' current psychedelic support project is the Zendo. Managed by a team of therapists, with about eighty volunteers, it operates at events in the US and Costa Rica, and relies on crowdfunding and donations. The Zendo is notable for its intent to act as a

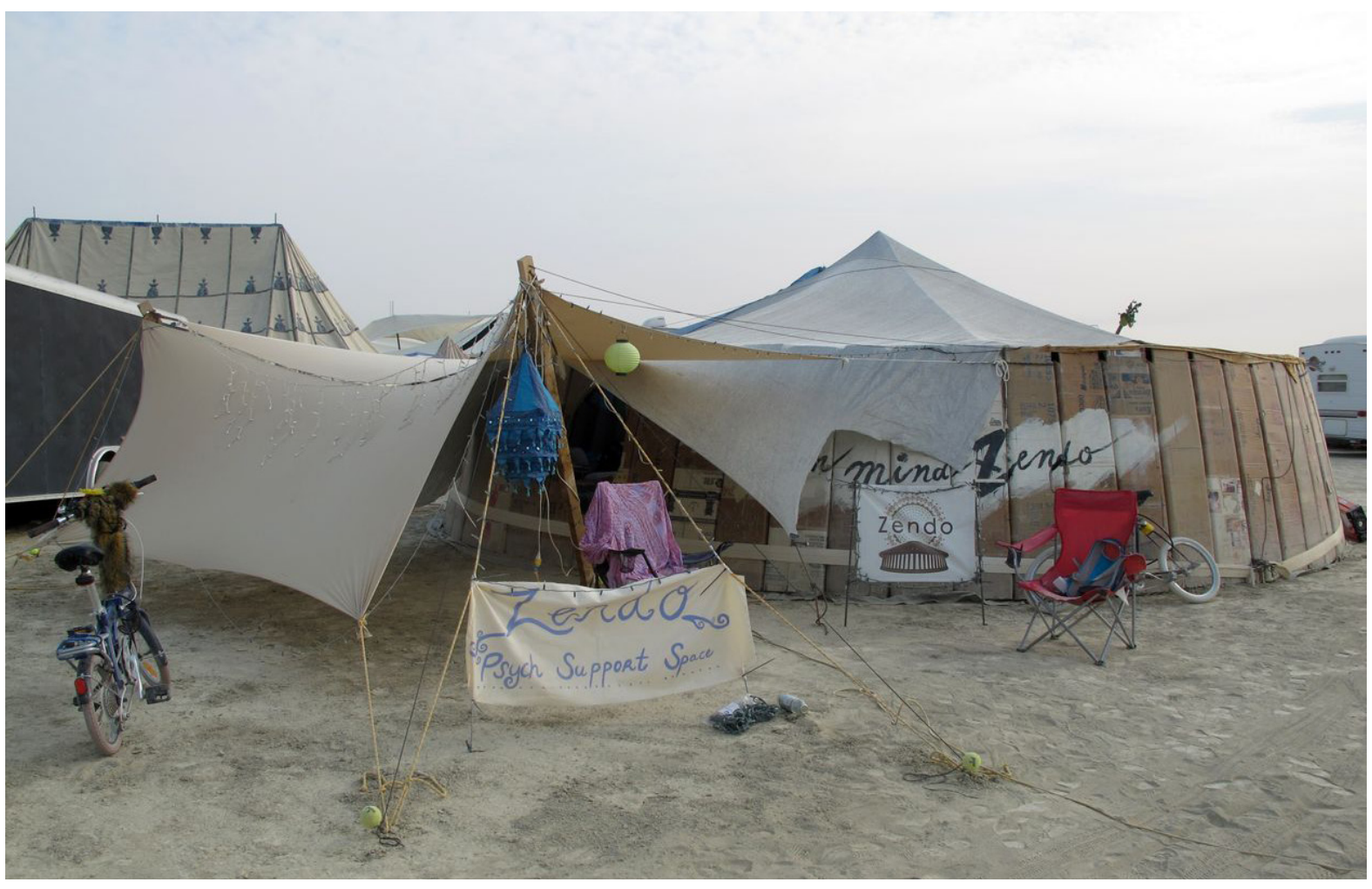

Figure 4. The Zendo setup at Burning Man. Photo credit: author (2014). 
"teaching hospital" for psychedelic therapists, in hopes that the law will eventually change to permit this type of therapy (Emerson et al. 2014: 34). However, such a change still seems a remote possibility under US drug policy. The provision of harm reduction facilities is illegal for event organisers under the RAVE Act of 2003, as this is considered to be "encouraging the use of drugs" (Blake 2015). Policy in Nevada, Burning Man's home state, is especially punitive; for example, it is a felony to possess a drug checking kit. As Emerson et al. (2014: 34) state, a previous MAPS project worked with the Black Rock Rangers-Burning Man's own community safety group-from 2003 to 2008, but was forced to shut down as harm reduction became increasingly criminalised; today the Zendo is not connected with the organisers of Burning Man. Zendo workers must, therefore, find an accommodation between the values of psychedelic discourse and the representatives of a mainstream culture who regard harm reduction as dangerously radical.

Another feature of the US festival landscape is the typically heavy police presence, including many undercover police. Warnings not to talk about drugs with anyone outside one's own camp are passed around Burning Man and broadcast on the city radio station BMIR. As a result, silences attend both sides of the relationship between the Zendo and those it seeks to support. Since open provision of harm reduction at events can be problematic in the US policy climate, the Zendo takes the precaution of advertising as "psych support" rather than psychedelic support. Furthermore, visitors and potential visitors are reluctant to discuss their drug consumption due to the climate of distrust arising from policing strategies. This reticence and the absence of checking facilities complicates the processes of formulating care strategies and predicting how cases will progress.

Possibly due to the Zendo's low profile, its rates of visitor participation tend to be much lower than those of Kosmicare at Boom, though the event is considerably larger (seventy thousand compared to Boom's forty thousand in 2014). In 2014, the Zendo was moved from its previous central placement to a remote location with its case total for the week falling by about half, to fifty-five. For comparison, Kosmicare at Boom 2014 had just short of four hundred cases. While there are other possible explanations for this dramatic disparity, such as Burning Man's ethos of self-reliance or its structure of close-knit, supportive camps, the possibility cannot be dismissed that a significant number of Burners who might have benefited from the help of the Zendo may have been afraid to ask, unaware of the Zendo or unable to find it.

\section{KOSMICARE UK}

More informal and emphatically peer-based compared with the Portuguese organisation, Kosmicare UK (KCUK) is linked with it in name only, though many KCUK volunteers have also worked at Boom. The core identity of most KCUK volunteers is that of the experienced psychedelic user supporting those with less experience, though some are also therapists. The organisation is smaller-scale than the others, running on donations from visitors and small contributions towards expenses by event organisers. The tents and field 


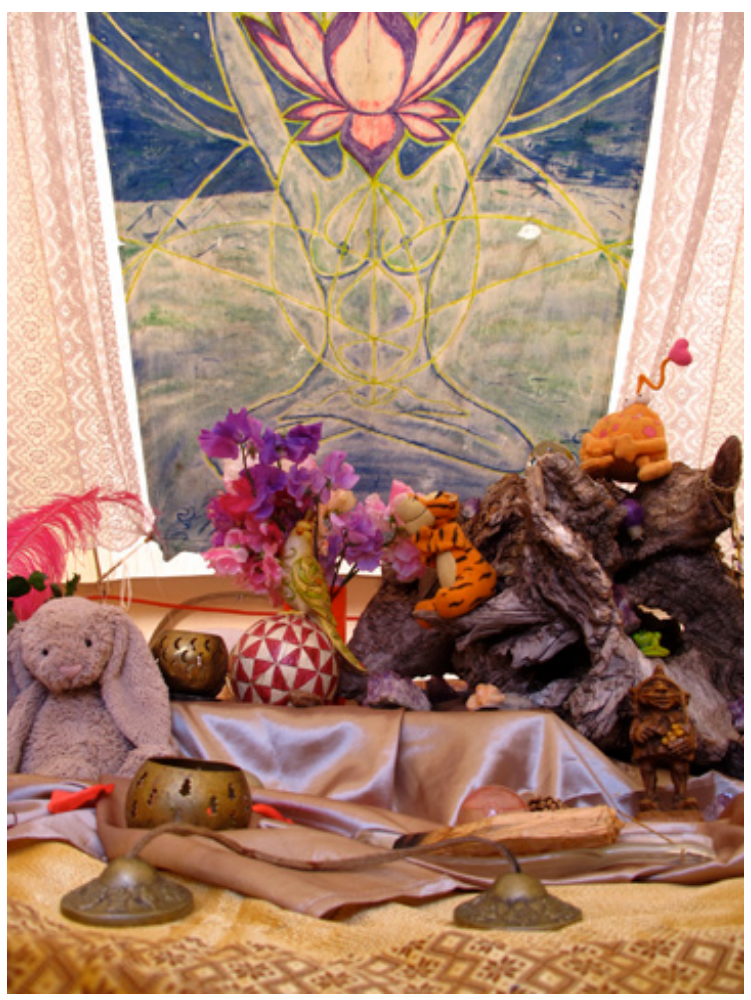

Figure 5. The altar in the main care space at Kosmicare UK.

"Lady Kosmicare" painting by Karin Silenzi de Stagni. Photo credit: author (2014).

kitchen are the managers' own, shifts of two or three are fielded, and there is no medical presence on staff. Of the three groups in this study, KCUK are the most open about their support of the psychedelic discourse.

This openness can cause problems in a policy climate which appears to be growing more punitive. Though the medicalisation approach to harm reduction was pioneered in the UK, reaching a peak of popularity there during the New Labour years (1997-2010), the subsequent Conservative/Liberal Democrat government reinstated supply and demand eradication as its central approach (HM Government 2010). At festivals, front-of-house drug checking is not possible under UK law at the time of writing. Psychedelic support is not illegal, but organisers of larger events, under the supervision of local councils and police, are wary of giving any indication that they are condoning drug use. In recent years many UK festivals have been subject to last-minute, unaffordable policing fee increases, which in most cases amount to a de facto shutdown (for one example, see Resident Advisor 2010). Thus, even if KCUK gains admittance to these events, their presence may go unacknowledged and unpublicised by the organisers, and problems often occur with visibility, infrastructure supply and integration - or lack of-with other on-site support services.

Each of the three organisations has been shaped by the policy climate within which it operates. All experience conflicts and dissonances between the values of transformational festival culture and the local policy climate. In the more punitive regimes, the organisations' 
values run counter to policy and to prevailing opinion, and if made explicit these conflicts can result in the abrupt termination of their work at the events.

Despite these difficulties, all three groups, and psychedelic support as a movement, appear to be undergoing a spurt of growth and formalisation. Kosmicare have begun to release quantitative findings on the efficacy of their intervention (Carvalho et al. 2014). An international collaboration between support workers, the Manual of Psychedelic Support, has codified many formerly fluid and ad-hoc working practices (Oak et al. 2015). KCUK is currently applying for charity status. The support groups' methods, results and values, which formerly tended to be implicit and shared among practitioners, are becoming increasingly explicit, codified and public. The groups are facing choices about the discourses and contexts they will use to frame this information.

One possible frame is that of harm reduction. It is now the core paradigm in Portugal, with a history of political influence in Australia and the UK (O'Malley 2002: 280) and for a short time in the US (Marlatt 1996: 785). As such, it can be seen as providing a quasi-respectable banner behind which drug policy reformers can rally. However, harm reduction is a concept freighted with assumptions and axioms which conflict with those of psychedelic culture, or exacerbate pre-existing problems within the culture. The following section examines the academic literature on harm reduction and considers its origins, in order to understand the implications for psychedelic support projects and the possible risks inherent in adopting harm reduction as their dominant discourse.

\section{Harm Reduction: a Brief History of an IDEA}

Harm reduction began as an advocacy movement by a group of Dutch heroin users, the "Junkiebond", who first went public at the beginning of the 1980s (Blok 2008). The movement set out to offer an alternative to the then popular approaches to drug use: attempts at supply and/or demand eradication, and "abstentionism" or use reduction. Instead, this approach focused on the reduction of "risk behaviours" such as the sharing of needles. The original approach was pragmatic and had peer-based services at its heart, on the basis that "drug users themselves know best what their problems are" (Wijngaart 1991, cited in Marlatt 1996: 784) — this is now known as the "Dutch model". Marlatt (1996: 785) describes an awareness, among early US harm reduction advocates, that drug use transpired in a complex social context and that marginalisation and inequality contributed both to the likelihood of drug use and the harm arising from it.

However, the concept mutated throughout the 1990s as it was adopted in other countries, losing many of its progressive aspects. The brief enthusiasm for the approach in the US swung back towards a more punitive neoconservatism. The emerging "UK model" replaced the focus on peer support with medicalisation. Awareness of the social context of drug use receded, replaced by a more neoliberal view of the drug user in which use was seen as merely a matter of free, individual choice (O'Malley 2002: 280), isolated from social issues and problems, and addiction was perceived as a "disease of the will" (Valverde 1998). 
Despite attempts to uproot or reconceptualise this approach, the neoliberal view of the self remains implicit to harm reduction rhetoric and practice. Delineated vividly by Rose (1996: 44), the neoliberal subject is a rational, choice-making individual whose ostensibly free choices and projects of self-government and self-improvement are in fact manifestations of internalised micro-processes of power which enable those in authority to govern "at a distance". Rather than being seen as part of a community, neoliberal subjects are entrepreneurial and competitive. This view of the self has various implications for harm reduction: dislocation of the user from their community or society; over-emphasis on rationality at the expense of pleasure (Moore 2008); and the portrayal of the addict (and by extension, drug users in general) as one who has misused their free will by making a bad-that is, irrational and irresponsible-choice.

Thus, within policy and practice, drug users became increasingly demonised. Moving further from the "Dutch model", a deep divide developed between drugs workers and users, although involvement of users in their own treatment is still a nominal goal (Onsia, 2014). Concepts of harm shifted, foregrounding harm done by drug users to communities through crime (Hunt and Stevens 2004: 334-5).

This shifting concept of harm has faced sustained critique recently. It has been said to lack an evidence base (Nutt, King and Phillips 2010: 1564), and to neglect large-scale harm caused by government agencies and policies (Rhodes 2009: 196). Further, regarding psychedelics, critics such as Tupper (2008: 297-303), Emerson et al (2014: 28) and Tennison (2012: 1-12) take issue with the focus on harm-which they consider to be relatively minimal - at the expense of the therapeutic and social benefits psychedelics could provide. This view is shared by many support workers.

Thus harm reduction discourse may be something of a poisoned chalice for the psychedelic support movement. The benefits which the discourse can confer in terms of respectability and legitimacy may not compensate for the difficulties of attempting to reconcile the values of transformational festival culture and harm reduction. The communal, fluid view of "self" and "other" within the transformational festival contrasts with the conception of self in harm reduction discourse: isolated and competitive, within a model where loss of self-mastery constitutes failure and weakness. Similarly, views of drug users as potentially engaged in valuable practices, and deserving of respect, conflict with mainstream portrayals as abject, criminal and will-impaired. While the drugs of choice in transformational festival culture are predominantly psychedelics (valued as cognitive tools or "teachers") and recreational drugs which facilitate dancing, the underlying assumptions of harm reduction discourse are shaped by heroin and other highly addictive substances. Finally, peer support is integral to care initiatives at transformational festivals; Leung (2010) portrays care spaces as developing organically from practices of informal care by "strangers and friends" within the festival. Mainstream drugs organisations, on the other hand, perceive support workers as distinct from (and at worst, superior to) current users. 
Many of my participants expressed their discontent with the terminology of harm reduction and were reluctant to use it. Nonetheless, this approach permeates the world of psychedelic support, leading to explicit and implicit tensions in areas where the two discourses intersect. The final sections use fieldwork findings to explore some of these areas.

\section{Open and Closed Care Spaces}

Tangible expressions of the two competing discourses, and clashes between them, can be observed at the physical boundary between care spaces and the festival. At KCUK, which subscribes more to psychedelic culture discourse than that of harm reduction, the care space-an outdoor campfire area, a large army tent for more talkative visitors and a bell tent divided into private spaces-is designed to present few barriers to entry. KCUK workers are aware that visitors may feel too shy, wary or ashamed to ask for help immediately, especially in the context of the UK drug laws where admitting use can be risky. Thus the open campfire area acts as a low-commitment stage in the establishment of trust. Space within the bell tent is carefully managed, but on the whole KCUK's configuration reflects the psychedelic discourse of the collective-minded, fluid self and the need for a porous boundary between visitors and support workers. This approach does have its disadvantages, in that it can be difficult to keep track of more mobile visitors and their friends at busy times.

In its earlier iterations, Kosmicare at Boom was similarly open, incorporating a social space. However, as representatives not only of psychedelic culture but of Portugal's innovative drug policy, since 2010 Kosmicare have been keeping detailed records to measure the efficacy of their intervention. Each visitor's mental state is evaluated by their sitter on arrival and departure, using a form with seventy-five questions. To enable this monitoring process, the compound has been fenced, with a single entrance via the front desk, and entry has been restricted to sitters and visitors. Results to date have been encouraging: "Pre-post mental state evaluation showed statistically significant difference $(\mathrm{p}<.05)$ confirming crisis resolution" (Carvalho et al. 2014: 1). For many volunteers, the research project is a powerful source of credibility for psychedelic support, part of an increase in efficiency which has generally been warmly welcomed and considered to have made caregiving easier. On the other hand, some had reservations about the increase in formality, the need for a fence and the complexity of the assessment forms, changes which they felt had moved the atmosphere of the space towards that of a medical facility and hindered the caring process.

Kosmicare's self-auditing project draws upon harm reduction discourse rather than that of the transformational festival. Auditing is part of the neoliberal project; increasingly, experts in every institution are required to provide detailed quantitative evidence that their methods work (Rose 1996: 44), while for individuals the notion of empowerment "recruits people into active self-management" (Bondi 2005: 504). As we saw earlier, transformational festivals allow participants to experience a temporary suspension of their usual identity as a modern competitive self-monitoring subject-whether on the dance floor at events like Boom (St John 2012: 116), through cathartic mass ritual such as the burning of the 


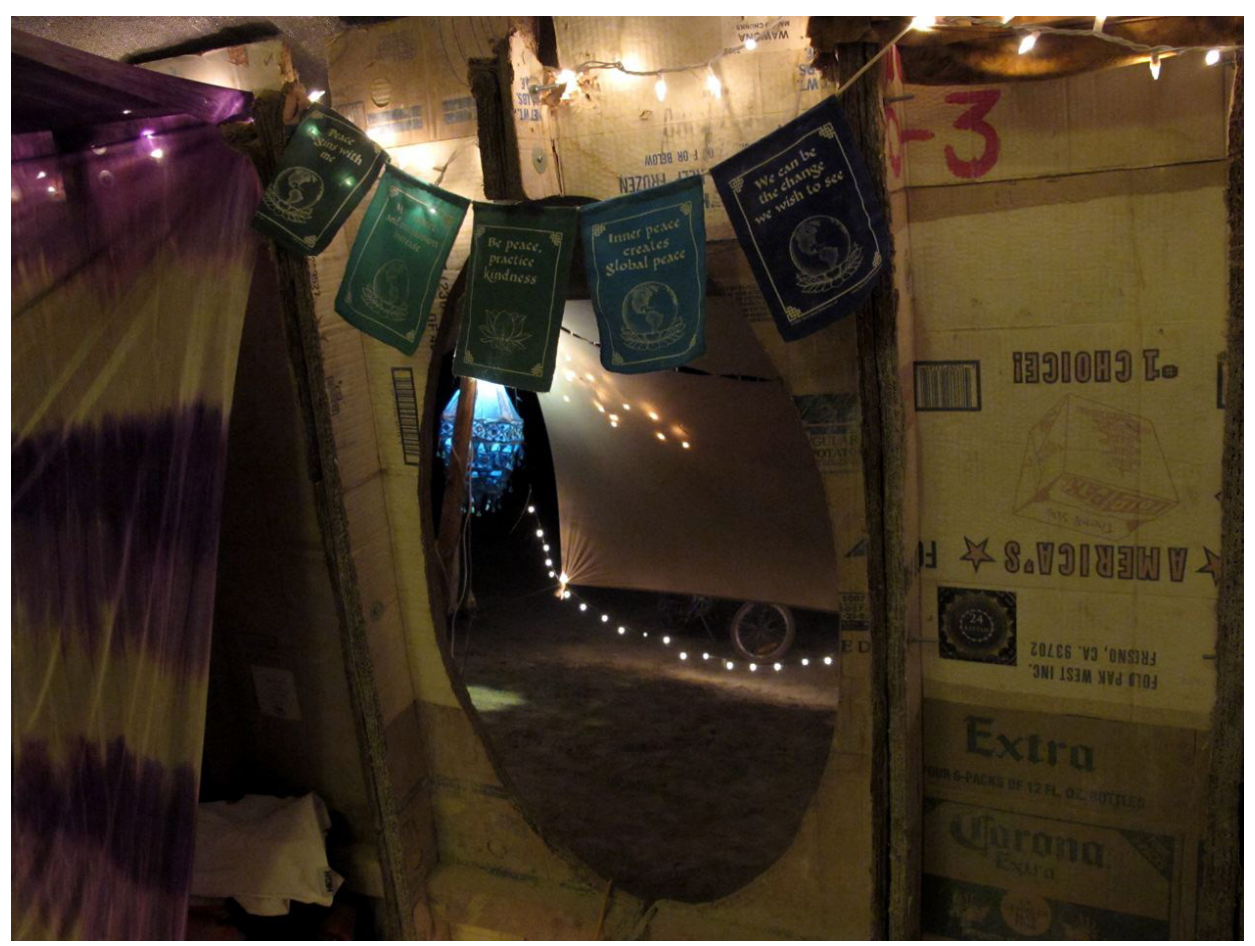

Figure 6. Doorway of the Zendo. Photo credit: Author (2014).

Temple at Burning Man (Gilmore 2010: 93), or simply through immersion in temporary community (Kozinets 2010: 36). Some volunteer respondents suggested that formalisation was seen as an incursion of the "real world", with its monitoring, bureaucracy and efficiency, into festival space, disrupting this suspension. Others felt the shift to a more medicalised, monitored care space had restricted the range of experiences afforded by the space, excluding both recreational use and "sacramental" use (that is, in a ceremonial fashion with the intent of spiritual growth). For some of these respondents, this concern reflected a wider anxiety: they saw medicalisation of psychedelics as a potential threat to transformational festival values, commodifying the substances and restricting their use to medical contexts, away from festive crowds and dance floors. In their view, one discourse had the potential to erase the other.

\section{CONCEPTIONS OF USE AND USERS}

The transformational festival scene distinguishes itself from more corporate festivals by its emphasis on personal growth, as opposed to consumption and hedonism. For many of my respondents, recreational use practices at the transformational festival are intricately bound up with therapeutic or sacramental use. One participant said, in relation to "wandering" on psychedelics at Burning Man, "...you get a lot of healing done. A lot of that is not that verbal... people are dancing, moving, trying to integrate stuff". For him, dance was associated 
with recreational modes of use, but also central to the transformational process. However, others are more critical of what they see as purely recreational use. A participant described Boom as "a wasted opportunity" for spiritual growth, saying there should be more explicit spiritual teachings available throughout the site and that the festival was "devolving... into an escapist, hedonistic free-for-all". Another had begun to feel that the loud dance music at Boom was an impediment to safe psychedelic use, rather than a catalyst for transformation. It is perhaps inevitable that such diverse value judgments about different modes of drug use will be made. However, a few participants went further, to make value judgments about the types of user-an attitude which meshes with mainstream harm reduction discourses in potentially damaging ways.

The harm reduction and transformational festival discourses involve contrasting views of "self" and thus of "self-control". In keeping with the neoliberal foundations of the discourse, in mainstream harm reduction, loss of self-control tends to be portrayed as a sign of a bad choice which has led to the impairment of one's conscious will. At worst, the will-impaired are seen by drugs workers as deficient in full personhood and without entitlement to respect. This attitude is linked with the gradual transformation of harm reduction from a peerbased movement to one in which there is a broad divide between workers and "citizens" (a term for users), and the culturally predominant portrayals of users as criminal, irresponsible and dangerous have been accepted. Interview participants in the UK, and a few elsewhere, tended to describe on-site medical staff and security as representatives of this approach, with a hostile, judgmental and patronising attitude towards drug users in difficulty.

Psychedelic support training sessions propose an alternative view, in keeping with the more fluid concept of self within psychedelic culture. Volunteers are encouraged to respect visitors in deep altered states, which may indicate valuable internal processes-as one participant said, "We don't know if they are meeting God". Respect for visitors is accompanied by perception of support workers as visitors' equals. Due to the emphasis on peer support, trust is established; visitors are thought to feel safer with "a festival person... not a uniform person", as one participant put it. Nonetheless, in the comments of a few participants a type of user emerged, considered to be hedonistic and reckless, who did not seem to receive equal respect: "There will always be stupid people doing stupid things", was one position. Sometimes these users were portrayed as outsiders, not in tune with the values of transformational festival culture.

In this context, it is perhaps unsurprising to see some commentators within the field of psychedelic support attempting to counter public fears that the substances are inherently harmful with the idea that harm generally stems from improper use, or indeed the characteristics of particular users. In the foreword to The Manual of Psychedelic Support (Oak et al. 2015: 9), Danforth attributes problems with psychedelics to, among other factors, "problematic mindset [and] lack of ego strength". Similarly, Móró and Rácz (2013: 6) write: "Hallucinogenic drug use in a party environment may occasionally turn into a bad trip, especially for unprepared and non-experienced persons with an unstable worldview and an irresponsible attitude toward mind-altering substances". 
A substantial proportion of psychedelic crises and other drug emergencies at EDM festivals may indeed be associated with lack of experience, knowledge or preparedness (my observations seemed to support this). However, emphasising these causes of difficult experiences while ignoring other possibilities has problematic implications. In keeping with the damage control view of psychedelic support, this explanation tends to portray such difficulties as the regrettable mishaps of neophytes rather than welcome opportunities for growth which may occur at any point in a user's life. This represents a shift away from the ethos of the transformational festival, to which these experiences are fundamental, in the direction of mainstream harm reduction.

More concerning, this view of drug-related crisis may result in victim-blaming: a visitor's difficulties may be taken as sufficient evidence that the visitor has acted irresponsibly. Many factors contributing to drug-related harm at festivals can be seen as systemic and exacerbated by national and local drug policy, such as the unrestricted use of adulterants, the ongoing development of new and unpredictable NPS as older drugs are banned, or the unavailability of checking services to offset these problems. In this context, explaining difficult psychedelic experience as "irresponsible" appears consistent with neoliberal ideology in "transfer[ring] all responsibility for well-being back to the individual" (Harvey 2005: 76). This way of thinking about drug use may disrupt the bond between visitors to support services and their sitters by making sitters more open to mainstream harm reduction discourses, whereby drugs workers are seen as fundamentally separate from users, who are subjected to othering or abjection. Thus the strengths of peer support, in which workers are perceived as equals and trusted by visitors, could be greatly diminished, and some of the transformational potential of these events impeded.

\section{CONCLUSION}

The discourse of transformational festival culture contrasts in a number of ways with that of currently popular approaches to harm reduction based on medicalisation and the "UK model". These points of contrast include two distinct conceptions of self (one holistic and transpersonal, the other rational and isolated), different conceptions of psychedelic use (one which considers a substance as a cognitive tool or teacher, the other drawn from the world of heroin addiction and focused on harm and crisis) and different approaches to the support of drug users. Within hostile regulatory climates, the adoption of harm reduction discourses carries less risk for psychedelic support organisations than openly espousing those of psychedelic culture. However, the relevance and utility of the harm reduction approach is limited when applied to psychedelic crises at transformational festivals, and may in fact diminish support groups' ability to connect with users and reduce harm in these cases. Nonetheless, the support groups' work at festivals-drawing on both discourses-provides an ever-growing body of evidence that standard harm reduction principles are oversimplified. This work points towards a possible future in which all routes to transformation remain open. 


\section{REFERENCES}

Blake, Mariah. 2015. “This Law Made It a Lot More Dangerous to Take Ecstasy”. Mother Jones, January 9. < http://www.motherjones.com/politics/2015/01/joe-biden-raves-mdma-death> (accessed 31 January 2015).

Blok, Gemma. 2008. "Pampering 'Needle Freaks' or Caring for Chronic Addicts? Early Debates on Harm Reduction in Amsterdam, 1972-82". Social History of Alcohol and Drugs, Spring: 243-61.

Bondi, Liz. 2005. "Working the Spaces of Neoliberal Subjectivity: Psychotherapeutic Technologies, Professionalisation and Counselling”. Antipode 37(3): 497-514. <http://dx.doi.org/10.1111/j.0066-4812.2005.00508.x $>$.

Carvalho, Maria Carmo, Mariana Pinto de Sousa, Paula Frango, Pedro Dias, Joana Carvalho, Marta Rodrigues and Rodrigues, Tania. 2014. "Crisis Intervention Related to the Use of Psychoactive Substances in Recreational Settings - Evaluating the Kosmicare Project at Boom Festival". Current Drug Abuse Reviews 7: 81-100. <http://dx.doi.org/10.2174/1874473708666150107115515>.

Dearling, Alan. 2012. Travelling Daze. Eyemouth: Enabler Publications.

Duffy, Maureen, Gordon Waitt, Andrew Gorman-Murray and Chris Gibson. 2011. "Bodily Rhythms: Corporeal Capacities to Engage with Festival Spaces". Emotion, Space and Society 4: 17-24. < http://dx.doi.org/10.1016/j.emospa.2010.03.004 >.

Echenhofer, Frank. 2012. "The Creative Cycle Processes Model of Spontaneous Imagery Narratives Applied to the Ayahuasca Shamanic Journey". Anthropology of Consciousness 23(1): 60-86. <http://dx.doi.org/10.1111/j.1556-3537.2012.01057.x >.

Emerson, Amy, Linnae Ponté, Lisa Jerome and Rick Doblin. 2014. "History and Future of the Multidisciplinary Association for Psychedelic Studies (MAPS)". Journal of Psychoactive Drugs 46(1): 27-36. < http://dx.doi.org/10.1080/02791072.2014.877321>.

Gilmore, Lee. 2010. Theater in a Crowded Fire: Ritual and Spirituality at Burning Man. Berkeley, CA: University of California Press.

Harvey, David. 2005. A Brief History of Neoliberalism. Oxford: Oxford University Press.

Hetherington, Kevin. 1997. "Vanloads of Uproarious Humanity: New Age Travellers and the Utopics of the Countryside". In Cool Places: Geographies of Youth Cultures, eds. Tracey Skelton and Gill Valentine. 328-342. London: Routledge.

HM Government. 2010. Drug Strategy 2010: Reducing Demand, Restricting Supply, Building Recovery: Supporting People to Live a Drug-Free Life. Home Office.

$<$ https://www.gov.uk/government/publications/drug-strategy-2010--2> (accessed 31 January 2015).

Hughes, Caitlin Elizabeth and Alex Stevens. 2010. "What Can We Learn from the Portuguese Decriminalization of Illicit Drugs?” British Journal of Criminology 50: 999-1022. <http://dx.doi.org/10.1093/bjc/azq038>.

Hunt, Neil and Alex Stevens. 2004. "Whose Harm? Harm Reduction and the Shift to Coercion in UK Drug Policy”. Social Policy \& Society 3(4): 333-42.

<http://dx.doi.org/10.1017/S1474746404001964>. 
Jones, Steven T. 2011. The Tribes of Burning Man: How an Experimental City in the Desert Is Shaping the New American Counterculture. San Francisco: CCC Publishing.

Kozinets, Robert V. 2002. "Can Consumers Escape the Market? Emancipatory Illuminations from Burning Man”. Journal of Consumer Research 29(1): 20-38.

<http://dx.doi.org/10.1086/339919>.

Krasnow, Stefanie Sara. 2012. "Transformational Festivals”. Reality Sandwich, July 26. $<$ http://realitysandwich.com/156783/tranformational festivals > (accessed 12 May 2015).

Marin, Louis. 1984. Utopics: Spatial Play. London: Macmillan.

Marlatt, G. Alan. 1996. "Harm Reduction: Come as You Are". Addictive Behaviors 21 (6): 779-88. < http://dx.doi.org/10.1016/0306-4603(96)00042-1>.

Moore, David. 2008. "Erasing Pleasure from Public Discourse on Illicit Drugs: On the Creation and Reproduction of an Absence". International Journal of Drug Policy 19: 353-58. < http://dx.doi.org/10.1016/j.drugpo.2007.07.004 >.

Móró, Levente, and Jószef Rácz. 2013. "Online Drug User-Led Harm Reduction in Hungary: A Review of 'Daath." Harm Reduction Journal 10(18). <http://dx.doi.org/10.1186/1477-7517-10-18>.

Nutt, David, Leslie A. King and Lawrence D. Phillips. 2010. "Drug Harms in the UK: A Multicriteria Decision Analysis". The Lancet 376(9752): 1558-65. <http://dx.doi.org/10.1016/S0140-6736(10)61462-6>.

Oak, Annie, Jon Hanna, Kaya, Svea Nielsen, Twilight and Zevic Mishor, eds. 2015. The Manual of Psychedelic Support. Psychedelic Care Publications.

O’Malley, Pat. 2002. "Drugs, Risks and Freedoms: Illicit Drug 'Use' and 'Misuse' under Neoliberal Governance”. In Crime and Community Safety: New Directions, eds. Hughes, McLaughlin and Muncie. 279-296. London: Sage.

Onsia, Martijn. 2014. Project Event Report: SNAP (Safer Neighbourhood Approach). < $\underline{\text { https:// }}$ snapnews 1.files.wordpress.com/2014/08/event_report_en.pdf $>$ (accessed 12 May 2015).

Pike, Sarah. 2011. "Desert Goddesses and Apocalyptic Art: Making Sacred Space at the Burning Man Festival". In God in the Details: American Religion in Popular Culture, eds. Eric Michael Mazur and Kate McCarthy. 154-73. London and New York: Routledge.

Purdue, Derrick, Jörg Dürrschmitt, Peter Jowers and Richard O’Doherty. 1997. "DIY Culture and Extended Milieux: LETS, Veggie Boxes and Festivals”. Sociological Review 45 (4): 645-67. <http://dx.doi.org/10.1111/1467-954X.00081>.

Resident Advisor. 2010. “Glade Festival 2010 Cancelled.” Resident Advisor. May 11. <http://www.residentadvisor.net/news.aspx ?id=12167> (accessed 16 May 2015).

Rhodes, Tim. 2009. "Risk Environments and Drug Harms: A Social Science for Harm Reduction Approach”. International Journal of Drug Policy 20(3): 193-201. < http://dx.doi.org/10.1016/j.drugpo.2008.10.003>.

Rose, Nikolas. 1996. "Governing 'Advanced' Liberal Democracies”. In Foucault and Political Reason: Liberalism, Neo-Liberalism, and Rationalities of Government, eds. Andrew Barry and Thomas Osborne. 37-64. Chicago: University of Chicago Press.

St John, Graham. 2001. "Alternative Cultural Heterotopia and the Liminoid Body: Beyond Turner at ConFest". Australian Journal of Anthropology 12(1): 47-66. <http://dx.doi.org/10.1111/j.1835-9310.2001.tb00062.x $>$. 
- - 2012. Global Tribe: Technology, Spirituality and Psytrance. Sheffield: Equinox.

- - . 2013. "Writing the Vibe: Arts of Representation in Electronic Dance Music Culture". Dancecult: Journal of Electronic Dance Music Culture 5(1). $<$ http://dx.doi.org/10.12801/1947-5403.2013.05.01.11>.

Tennison, Michael. 2012. "Moral Transhumanism: The Next Step". Journal of Medicine and Philosophy 37(4): 405-416. <http://dx.doi.org/10.1093/jmp/jhs024>.

Tramacchi, Des. 2000. "Field Tripping: Psychedelic Communitas and Ritual in the Australian Bush”. Journal of Contemporary Religion 15(2): 201-213. $<$ http://dx.doi.org/10.1080/13537900050005976>.

Tupper, Kenneth W. 2008. "The Globalization of Ayahuasca: Harm Reduction or Benefit Maximisation?” International Journal of Drug Policy 19(4): 297-303. $<$ http://dx.doi.org/10.1016/j.drugpo.2006.11.001>.

Turner, Victor. 1969. The Ritual Process: Structure and Anti-Structure. London: Routledge. Valverde, Mariana. 1998. Diseases of the Will: Alcohol and the Dilemmas of Freedom. Cambridge: Cambridge University Press.

Zendo Project. 2013. The Zendo Project Harm Reduction Manual: Burning Man 2013. MAPS. $<$ www.maps.org/images/pdf/Psychedelic-Harm-Reduction-2013.pdf > (accessed 15 May 2015).

FILMOGRAPHY

De Stagni, Karin Silenzi. 2013. "Kosmicare". Vimeo. 28:01. Video of a talk presented at Breaking Convention, Greenwich University, July 12 2013. <http://vimeo.com/78241633> (accessed 12 May 2015).

Leung, Jeet Kei. 2010. "Transformational Festivals". Presented at TEDx Vancouver, Vancouver. $<$ http://tedxtalks.ted.com/video/TEDxVancouver-Jeet-Kei-Leung-Tr $>$ (accessed 12 May 2015). 